\title{
Positive climate changes
}

\author{
Lara Mosunmola Lalemi, PhD student at the University of Bristol and founder of the Creative Tuition Collective, \\ shares with Nature Chemistry some of her projects - from climate chemistry to social justice - to improve our \\ environment in all senses of the term.
}

\section{What are you working on at the moment?}

I am working on many projects, but I will give you my top four right now. The first is my postgraduate degree in atmospheric aerosol science. I am passionate about using chemistry to help solve global issues, so I chose an area of research associated with a better understanding of climate change.

Another one of my ambitions lies in making STEM education more accessible and equitable to young people from low-income backgrounds; I have approached this by founding a non-profit organization called Creative Tuition Collective. We will provide free STEM tuition, extracurricular informative workshops, for example on financial literacy, as well as group mental health sessions to young people at the secondary-education level. We are currently taking applications for our newly launched six-month pilot scheme; I am excited to see how our support can boost the confidence of the people who participate.

The COVID-19 pandemic has exacerbated the socioeconomic inequities of the UK education system - for example, over 1 million families lack digital access in the UK. In collaboration with the University of Bristol, Creative Tuition Collective and DigiLocal Bristol, we led the Digital Together project that is donating desktop computers from the university to different community groups, such as Babbasa - a social enterprise that supports disadvantaged young people at the start of their professional life - as well as local families.

Lastly, I am leading a group on the decolonization of the science curriculum - work to actively dismantle the solely Eurocentric narratives that dominate the science education system - with a diverse team of national and international academics, who provide workshops to universities and organizations across the UK. Decolonization is often a misunderstood term and we work to provide academics with a better understanding of what it is while also encouraging the reformation of our STEM curriculum in order to diversify, equalize and broaden what is currently taught in higher education. We have worked at many UK universities, from St Andrews to Exeter.

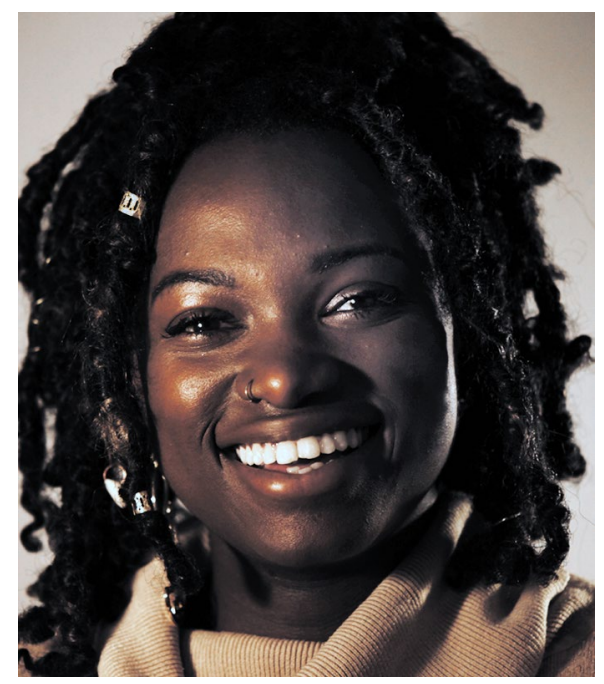

Credit: Helen Gaden

How did you get into atmospheric chemistry and climate-change research? I do love this story; it is only serendipitous and joyful to me. It all started in the lecture theatres of Prof. Dudley Shallcross, who was explaining atmospheric chemistry and the impact of climate change. I was enthralled and ready to act, whether through research or personal activism, so I undertook first a mini-research project and then a summer internship with Prof. Shallcross, working on carbonyl sulfide (OCS) atmospheric models. Much to my delight I was then selected for a project in aerosols with Dr Bryan Bzdek.

I grew to love aerosols, not just because we were able to use the brightest green $\mathrm{Nd}$ :YAG lasers I had ever seen to levitate particles (like a hover board), but because I was part of a passionate, supportive and innovative research group who have produced incredible work in aerosols over the past 13 years. Following this, I was encouraged to conduct a PhD in aerosol science with Dr Bzdek, funded by the Natural Environment Research Council (NERC), which I am currently completing.

You assess the effect of surfactants on the growth of aqueous aerosols into particles, and in turn clouds, through the oscillating droplet method. Can you tell us more about the techniques involved?
We know that atmospheric aerosols have a variety of environmental effects, including the part they play in cooling the Earth's climate by serving as cloud condensation nuclei. However, the extent of this cooling remains a large uncertainty.

The supersaturation barrier to aerosol particle activation, which dictates both the formation of cloud droplets and the microphysical properties of clouds, is influenced by the particle's surface tension. Climate models generally assume atmospheric aerosols have a surface tension equal to that of pure water during the activation step, however this may not be exactly true. In my work, I use the droplet oscillation method to quantify the surface tension of aqueous surfactants, inorganic and organic solutions - a technique first described by Lord Rayleigh in 1879 for non-viscous, force-free spherical drops and later adapted for surfactant solutions. Droplets of picolitre volume and 30-80 $\mu \mathrm{m}$ in diameter are reproducibly generated from a dispenser. When the droplet is formed, its shape initially oscillates before reaching relaxation, and those oscillations are characterized at a resolution of $1 \mu$ s. The droplet's surface tension is inferred from its oscillating frequency, time-resolved by stroboscopic imaging (500 ns). These measurements have shown that the surface tension of these surfactant-coated droplets is lower than that of water droplets, but also different from that of bulk aqueous surfactant solutions.

I study the influence of surfactants and organic acids on the surface tension of droplets because they are ubiquitous in our atmosphere and account for a significant percentage of atmospheric aerosol mass.

You also help people from all walks
of life to gain confidence and a sense of
belonging in the scientific community.
During the first year of your PhD you
organized a 'Being BME in STEM' event
(where BME stands for Black and minority
ethnic). Can you tell us about the event,
and some of the changes that were imple-
mented at Bristol University as a result?
Wow, this was a monumental event for
me and has led to many opportunities and
projects in my personal life as well within


and beyond the university. The conference progressed from keynote lectures to round-table group discussions, a panel discussion and a social gathering combined with elements of a career fair.

We first heard from Cleo Lake, Lord Mayor of Bristol at the time, about the significant contributions from Black and minoritized ethnic cultures to science throughout centuries. Dr Erinma Ochu $\mathrm{MBE}$ then shared some of the challenges she faced on her way to becoming lecturer in science communication and future media at the University of Salford, and how she works to foster positive interactions for herself as well as students of Black and other minoritized backgrounds in her lectures; this includes, for example, implementing a code of conduct.

Dr Emmanuel Adukwu, senior lecturer in biomedical science and employability lead at the University of West England, Bristol, discussed his academic career to date and how difficult (some) things were when he emigrated from Nigeria to the UK as a student. He also highlighted the importance of mentorship within the BME STEM community - from the perspectives of both mentors and mentees.

The delegates then broke into groups for round-table discussions that centred around four points: the recruitment and retention of Black and other minoritized ethnic groups in STEM education; how to protect students and staff from these communities from feelings of isolation; what an inclusive education system and working environment would look like - and what changes can be made to progress towards these.

These questions were then tackled by a panel composed of Dr Ochu and Dr Adukwu as well as Dr Mark Richards (senior teaching fellow and head of physics outreach at Imperial College), Prof. Fred Manby (professor of theoretical chemistry at University of Bristol), Prof. Christina Hicks (lecturer in political ecology at Lancaster University) and Nasra Ayub (undergraduate education officer at Bristol Students' Union). I found this to be a poignant section of the event because this format allowed for self-reflection from the panellists. I also would like to highlight that this was a diverse panel - not only visually, but also in terms of thinking. This is an important point when considering the current push towards diversity. Diversity doesn't automatically mean you will have diverse ways of thinking. Similarly, diversity without inclusion will perpetuate the same problems that are currently prevalent. We must recognize that diverse representation is not enough - it is a change in environment in our institutions that is crucial.
The event concluded with facilitators from each round table presenting their proposed solutions to the question they had been assigned (with prizes for the best contributors). As can be seen from the report, the event promoted healthy discussions of the issues under consideration as well as a very sensible set of solutions to present to the university. It also fostered a sense of solidarity amongst Black students and those from other minoritized ethnic groups, and provided a safe space for talking about their own experiences. After such heavily engaging sessions, it was only right to finish off the day with Somali and Spanish food and drinks, combined with a career forum where students from Black and other minoritized communities could talk to several companies about employment opportunities.

I learnt a great deal from this conference and with the support of Prof. Fred Manby, a brilliant ally, I propelled forward some of the suggestions made by the engaged audience to the equity, diversity and inclusion (EDI) committee in my department. Notably, we have since commissioned a board of photographs of inspirational Bristol scientists who happened to be people of colour to be displayed at the entrance of the University to change who students, staff and visitors see. Visibility is important.

You also founded the Creative Tuition
Collective, which provides not only free
tuition to pupils from low-income back-
grounds and marginalized communities
but also mental health and personal devel-
opment support. How did you develop this
holistic approach to education?

As I was growing up, my family afforded me many opportunities in life, and I have recently come to realize how useful these were. I had tutors in chemistry, mathematics and biology - all amazing women of colour who encouraged me to believe in myself and strive for the best that I could. I needed them, I struggled to grasp everything within school hours and though I had a natural aptitude for mathematical subjects, I continued to struggle in exams. Tutoring really can change lives. The Education Endowment Foundation has shown that tutoring can add up to five months' progress to a child's learning on average. However, it is currently expensive and therefore largely inaccessible for those who face socioeconomic disadvantage. From this, the tutoring side of Creative Tuition Collective was born.

Growing up in Britain as an intersectional minority is a very difficult experience in parts and I believe one of the problems that allowed for my inner inferiority complex to rule my young existence was the lack of an inclusive pedagogy in the school curriculum. Not once were we taught about people of colour in science, or in other areas either for that matter, apart from history. The only times I heard of my people's existence were rooted in oppression and violence, provoking a feeling of anger and inferiority. I questioned what Black people or people of colour had contributed to the knowledge of the world. By no coincidence I started to explore this question and found that their contributions to knowledge were beyond what I imagined - in particular there were a plethora of inventions, cures and techniques learned from continents we now call the Global South. Through Creative Tuition Collective, I wanted to impart this knowledge to students to inspire them and expand on what they know beyond the school curriculum. We wanted them to learn about all aspects of society, including how to manage money or understand politics, in order for them to become more confident, better prepared students than I was despite all I was given. For this reason, we brought in the idea of interactive workshops for student personal development.

Lastly, mental health is an important topic to me. I struggled with poor mental health when I was in school. I didn't understand my own brain and why it functioned in the way it did. I recognize now that I would have greatly benefited from mental-health support and guidance back in school but there were insufficient resources to support every student. Ten years on despite the increase in services available - there still is not enough support for students in managing their stress and mental conditions alongside their studies. Through these group sessions organized by our director of communications and wellbeing, Sarah Cooke, we want students to be able to talk about themselves, their worries and also their triumphs - in a safe and inclusive space so that they realize they are not alone. Creative Tuition Collective is offered to both neurotypical and neurodivergent students; we believe it is vital to tackle the topic of mental health alongside what we do.

\section{Creative Tuition Collective was built on the success of your workshops on decolo- nizing science. Can you tell us about this aspect of your work? \\ As I mentioned earlier, understandably decolonizing science (STEM) is a topic that is hard to comprehend due to the interplay between fields, including social sciences, and the fact that scientists are rarely taught how to interrogate the topic of science, largely seen as objective - which it isn't in its entirety. It is critical to understand how}


the science we know today was formed and its impact on society, both historically and currently, in order to comprehend how it continues to uphold the toxic power dynamics that rule our world, institutions and industries.

I endeavoured to gather brilliant scientists to work with me on developing a workshop that is an introduction to the concept of decolonization. The team comprises both students and academics; we work together, and challenge each other, to produce bespoke presentations and facilitation for universities starting to tackle the topic. We also offer post-workshop material and support, and ensure that there is energy to continue this work as it is important to keep in mind that it has no endpoint. Decolonization is a continuous but necessary process. With the Advance HE charity, we have started developing 'decolonizing the science curriculum' resources such as an animation and videos, and we are currently looking for support and funding to continue producing this work.

For me, the purpose of this work is to expand our educational institutions to other epistemologies, teaching techniques and methodologies. I strive for further involvement of students in curriculum design, and to challenge how we test or assess knowledge. These projects are all facets of developing our education systems to a place where it is once again fun to learn and students can discover without constraints. If we hold a mirror up to colonialism, we can see it was born from ideas of extractivism, exploitation but also curiosity; I want to now lead with curiosity to explore whether decolonization can be a key to engaging more students, academics and non-academics in developing our science and society.

I am continuously inspired by James Baldwin who once said: "Not everything that is faced can be changed but nothing can be changed until it is faced."

\section{Where did you find support to be able} to achieve what you have so far?

The answer is mentors. I realized at an early age that mentors were going to be integral to my journey because my first mentors were my family. My mother, father and brother all mentored me to blossom into the person I am today and continue to do so, they are the first layer of the mentor cake.

The second layer, a rather delectable one at that, were my three tutors, a school teacher and my dance teacher. Never underestimate the power of a teacher to turn a student's life around. Teachers can be a phenomenal part of a student's success and the one that sticks out the most was my dance teacher. She was the first person to really notice I wasn't okay and ask me why. She would also teach and practice Spanish with me and built my confidence from the ground up. I shone brighter because of her belief in me.

The final scrumptious topping to the cake are the mentors I have met throughout my university journey. Anna Starkey, Prof. Nazira Karodia, Donna Speed, Donna Frater, Huw Griffiths and Dr Chris Russell. I name them because they mean a great deal to me. Even with the two previous layers, impostor syndrome set in at university and my ability to see myself in a subject like chemistry became very slim. I also want to highlight that most of my mentors have been white. In a lot of the work I do, people are striving to increase the representative figures from people of colour in STEM. Of course this is important but it doesn't mean that they should be responsible for mentoring all students of colour. This sentiment alone also puts pressure on those who are in these positions (or striving for them) to represent their entire community or ethnicity in a heavily white westernized environment - a hefty and impossible task in itself. Instead, my mentors didn't have to look like me; they embodied my beliefs, understood my energy and passion, taught me about work boundaries and nurtured me to a place where I started believing in myself. They (along with my supervisor) were able to encourage and guide me to a $\mathrm{PhD}$, something I never dreamt I was capable of doing. This is what great mentors do.

I now wish to pay what I have learnt forward and I have also started mentoring students.

\section{What are your plans for the future?} First and foremost, to complete my $\mathrm{PhD}-$ this will be one of my greatest challenges. At Creative Tuition Collective we plan to expand the tuition from six months to a full year so that students can benefit from tuition and develop a mentoring partnership with our tutors. Eventually, each cohort will be in Creative Tuition Collective for two years and will then become alumni. If possible, through donations, we also wish to begin a programme that will encourage students to discover arts, including spoken word poetry, radio presenting, fine art and music. What made me into the person I am today was my mother's investment in not just my formal education but also my artistic side; I was able to do dance, sport, art and music, which all developed my confidence and my ability to speak in front of a crowd. In order to build a student's confidence, we must consider more than just their academic intelligence but feed what they enjoy and can achieve in other aspects of life.

The ultimate goal is to encourage universities to carve out positions in all science departments to continuously assess the curriculum, run development workshops for staff and students, look after student well-being (by understanding their courses and the stresses they can be under and signposting where to go for additional help and guidance) and be responsible for EDI work. Such positions exist in universities in the USA and Canada. However, in the UK, this work is currently being tacked onto the workload of certain motivated academics, leading to a strain on their time and energy. Having dedicated positions for these topics would mean that students would be cared for as individuals rather than treated as a commodity. I strive for a more inclusive education system, which would in turn lead to a more equitable and engaged society.

\section{Interviewed by Anne Pichon}

Published online: 31 January 2022

https://doi.org/10.1038/s41557-021-00886-w

Competing interests

L.M.L. is the founder and CEO of Creative Tuition Collective (the not-for-profit organization mentioned in the article). 